\title{
Principles of spiritual and cultural activity
}

\author{
Rakhimov Asomiddin Anorboevich ${ }^{1}$ \\ 'Samarkand State University , "Pedagogy and psychology of preschool education" \\ teacher of the Department, Uzbekistan \\ Email:_rakhimov_a@umail.uz
}

\begin{abstract}
This article provides information on the principles of spiritual and educational activity and explains its role in the development of the student personality. Also, some directions of the organization of spiritual and educational activities in higher educational institutions were explained.

Keywords: educational reform, personality, education, upbringing, development, knowledge, democratic society, spirituality, enlightenment, activity, Principlesip, creativity, initiative, values, higher education institution.
\end{abstract}

\section{INTRODUCTION}

In the conditions of educational reform taking place in our republic, the most important thing is to educate people who are loyal to their homeland, People, mother, husband, nation, parents in every way. In the updated state system, the content of upbringing is updated in both maksad and functions. This update differs primarily in that education is built on the basis of the principles of humanism and democracy. As President Of The Republic Of Uzbekistan M. Mirziyoyev noted, " education is the most important and priority issue of any state and society, which decides not only today, but also tomorrow. Therefore, in our country, great attention is paid to this issue at the state level" [1, 353]. In fact, today the qualitative Organization of the educational and educational process is becoming more relevant than ever before.

Humanization and democratization of education the principlesypi students, teachers and educators develop their creative activity and independence, which serves as a guideline for their cooperation in the implementation of various socially useful works.

A special role is played by spiritual and educational activities carried out in higher educational institutions for the formation of creative activity, intellectual intelligence, moral potential, scientific worldview, their active participation in social and useful work with wide coverage.

Accordingly, we will consider in this article on the spiritual and educational activity in educational institutions, its planning, organization, principlesing forms.

Love for his country, Homeland, feelings of humanism is an age-old feature that is absorbed in the blood of our people. The issue of preserving these unique human qualities and further improving the free and Democratic upbringing of our children as worthy sons and daughters of Uzbekistan should be the main direction of our work in the sphere of spirituality. Therefore, it is necessary to clearly plan spiritual and educational activities in educational institutions, to create a system of spiritual and educational upbringing, to focus its forms and techniques on the formation of the spiritual and educational worldview of the younger generation. The sum of any upbringing, event, spiritual and educational activity will be targeted only in the destiny based on them, when certain rules and requirements are observed. These rules, requirements, bases are called "Principlesips" in pedagogical science.

Hence, spiritual and educational activity also applies to certain principlescypes. Principles of spiritual and educational activity-this is the expression of adherence to the direction, content, methods and organizational forms of educational activities organized in educational institutions in the max of upbringing a harmonious generation, the main requirements for the interaction of participants in the educational process. 


\section{MAIN PART}

Principles of spiritual and educational activity are considered as the sum of the requirements, rules that guide teachers and educators, it is determined by the tasks of educating a competent person and reflect its laws based on the universal education doctrine and achievements of scientific pedagogical knowledge. Therefore adhering to these Principles in the process of spiritual and educational activity increases its effectiveness in weight loss, developing a quality indicator.

Based on the current theories of world and national pedagogy, the principlesing of spiritual and educational activity can be grouped as follows:

$>$ social orientation of spiritual and educational activity principlesipi;

$>$ principles of volunteerism, Independence, play and romance;

$>$ the point of view of creativity, initiative, striving for innovation in the work the principle of approach from the point of view;

$>$ the planning of spiritual and educational activities and ensuring that the activities are compatible with the power of students;

$>$ the principles of regularity, duration, continuity and impressiveness of spiritual and educational activity;

$>$ it is the principles of taking into account the age and individual characteristics of educators in the organization of spiritual and educational activities.

Now we proceed to the description of the Principles of this spiritual and educational activity:

$>$ A principle of the social direction of spiritual and educational activity. This principles sip implies social development in the organization and implementation of spiritual and educational activities, connection with the development of the country's ideological, political, socio-economic and spiritual-cultural development, the content of work to be organized outside the classroom and the audience, the activities of circles, clubs, associations, as well as the basis for the achievements of Science, Technology, Culture, Art.

$>$ The principle of volunteerism of participation in spiritual and educational activities. This principle is a spiritual and educational activity organized in educational institutions by faculties, clubs, various sectors, clubs, etc. the G. the focus will be on the choice of the students participating in the study, depending on their interest, desire, ability, and on ensuring that these are voluntary. The principles of volunteerism also implies taking into account the volunteerism of the students, so as not to overexert and strain them, taking into account the fact that the extracurricular activities organized in educational institutions are not more than two.

> In spiritual and educational activity, students-principlesypes to take into account the independence, initiative, creativity of young people. This presupposes the need to organize spiritual and educational work on the basis of interests, initiatives of principle students. Any action should first of all be based on the independence of the students, the teacher-educator should authorize them, develop their activities. Then the students develop initiative, interests, creative abilities. They learn to perform any event independently on the initiative, with interest in a high-rise spirit. In them, a sense of self-control develops.

$>$ The principle of educational activities in the form of entertainment, romance. It is expedient to apply this principle mainly to junior and high school students. Because small and high school age students mostly feel more need for gaming activities. But the spiritual and educational activities organized in these educational institutions are aimed at the direction, content, methods, organizational forms of education, the main requirements for the interaction of the participants in the educational process.

$>$ Principle to take into account the age and individual characteristics of students in spiritual and educational activities. In this principles-out, the functions, content of the activities correspond to the age and level of preparation of students, and they should avoid adversely affecting their health, their worldview, their spiritual and moral potential, their mental intelligence.

To the saved principles outs of spiritual and educational activity based on their integrity, mutual cooperation, mutual complementarily, effective use of them, students ' educational, educational and 
developmental activities are guaranteed to be put on the target path, the formation of a harmonious person as a full-fledged person.

\section{THEORETICAL ANALYSES}

The purposeful organization, orientation of spiritual and educational activities is to determine its content with a clear definition and development. If the content and the plan are organized in a disproportionate way, the intended goal will not be realized. Accordingly, a person is brought up incorrectly, from which both society and man suffer, and the person himself. So it is necessary to clearly define the content and plan it correctly. Otherwise, the great thinker Bedil, as they say, if the architect did not correctly lay the first brick, the wall would still be crooked, even if it reached the stars. This opinion of Bedil is related to spiritual and educational activity. As long as it is necessary, therefore, to accurately visualize the content of spiritual and educational activity, to correctly specify and plan its directions.

Spiritual and educational activity is the process of finding, developing the content of intellectual intelligence and spiritual and moral potential in accordance with the goals and objectives of a particular society, enriching the inner world, which represents the essence of man in the quality of socio-cultural existence, encourages him to spiritual purification and Ascension. Accordingly, the definition and planning of the content of spiritual and educational activities carried out in higher educational institutions in the socio-political, economic and cultural development of society in the following directions is in demand.

* Organizational and educational work

* Ideological (ideological-political) education imposes on students social activity and attitude to study.

* Formation of the foundations of the scientific worldview, deepening and expanding knowledge, increasing cognitive activity.

* Education of universal, national ethics and culture of conduct.

* Beauty, elegance and artistic education.

* Education of love for the people of Labor and labor.

* Economic and environmental education and nature protection

* Increase the legal knowledge of young people.

* Health and physical fitness of students

○ to care about.

* Spiritual-educational and ideological work carried out with teachers and employees of the University.

* Work with parents and neighborhood.

* Spiritual and educational work carried out by public organizations (Youth Union, Trade Union, Women's Wing) at the University.

As noted above, in the process of studying all subjects in higher educational institutions, it is necessary to focus on increasing the spiritual and educational culture of students and on extracurricular activities. It is necessary for each student to understand the fundamental meaning of the concepts of "spirituality", "culture", to be aware of the sources of our national spirituality, to obtain independent free knowledge from these sources, to have the skills of studying. In our opinion, the directions of spiritual and educational activities organized in higher educational institutions are desirable if they are covered as follows:

Direction I: - it is planned to hold events on self-sufficiency, celebration of knowledge, celebration of Jubilee dates, teachers 'and mentors' day, Constitution Day, Vatan defenders ' day, religious holidays ("Ramadan" and "Kurban" celebrations), Pentecost, Navruz holiday, celebration of memory and honor day, Organization of excursions to historical monuments, Republic pilgrims, holding such contests as the year coach.

Direction II: - considering the young and individual characteristics of the students of ideological education, issues such as studying the information on the internal and external policy of our country, studying the works of the president of the Republic, getting acquainted with the decisions and 
information of the Oliy Majlis, studying the essence of the symbols of our state, getting acquainted with the activities

Direction III: - the culture of intelligent Labor, the activity of cognition and conscious attitude to reading, the education of the foundations of the scientific worldview. Conducting conversations, discussions, scientific practical conferences on such topics as" O'kish organ"," my interesting occupation"," my interests"," human and technical world"," life of famous people"," my dreams and interests"," the world I know and do not know"," for the development of Science", Organization of games" think, seek, find"," cheerful and resourceful", etc.the G.

IV direction: - Islam, which forms the basis of universal morality, issues of education and education, study of the teachings of our scientists, "lessons of etiquette", "spirituality and life", " life

Organization of round tables on topics such as " living and etiquette,

Discussion on "girls chastity", "pride of youth", "women's culture"

conversations on the etiquette of discussion, conversation, dressing, treatment, spend evenings, conferences.

V. Direction. :-a team of students and professors and teachers give information about wellknown artists, with the aim of developing aesthetic culture, establish meetings, make a speech on the topics of "music my life", "overcome the word heart, dress husnni", " World Inside-My World Bukhara sharifim", "I love nechun, Uzbekistan" production of stands, creativity, poets, writers, composers, actors, organizing meetings with directors, organizing conferences of readers: to organize clubs of artistic creativity, to go on excursions, to organize contests on etiquette beauty, culture of behavior, rules of taste and behavior.

VI . Direction: - with labor leaders, Heroes, Veterans organizing meetings: social-useful labor Saturdays, Sunday participation: technical creative clubs, clubs, participation in the work of remontbuilding detachments: "appreciate Labor", Production of stands" profession and labor"," my profession-honor": professions, labor showcases of gakhramonlari, "in the years of independence of our city" extraction of photomontage, etc.the G.

VII. direction: - Economic Education and nature protection:

giving information on economic knowledge, saving: conducting textbooks on the equipment of the training room, holding conversations on the preservation of teaching aids: Organization of stands "economy and education", "water obi-life": meetings with economists, accountants, bank Employees, Organization of question - and-answer nights.

VIII direction: - on increasing the legal knowledge of students-youth: education of high civil qualities in students-youth, the Constitution of the independent republic, feelings of respect for the laws: loyalty to the ideas of national independence, formation of intolerance to religious extremism and fundamentalism: conversation with people's deputies, employees of law-enforcement bodies, meeting, Organization of Question-Answer evenings: "your own home", " militia - my - period talabi "Organization of visual stands: traffic rules, Organization of the circle "young lawyer": "do you know the law?"conducting an examination contest.

IX direction: - to take care of the health and physical perfection of students. Organization of Morning health training in educational institutions: classes of physical education and Physical Culture, improvement of activities of clubs: attention of student-youth movement bodies: Organization of sports sections: development of tables of sports games, competitions held in the academic year: regular holding of sports games such as" kichik Universiada"," Olympiad reserves", wide promotion of healthy lifestyle and its active implementation: holding a contest

$\mathrm{X}$. Direction:-spiritual and educational activity carried out between teachers and students and youth. Organization of conversations, evenings on the topics of "spirituality - the cultism of the nation", "Islamic spirituality torch", "knowledge of Hadith - the science of life", "the angles of our spirituality", conducting hours of study of laws and normative documents such as "Constitution of the Republic of Uzbekistan", "labor laws", "Family Code", "Criminal Code", "Law on education", "national program of Personnel Training", "teaching honor", "skills of educators", "organize evenings on the topics" coach".

XI.direction:-working with parents and neighborhood. In order to determine the pedagogical data of the parents of students and young people on the territory of the educational institution, the 
organization of examination competitions on "spiritual and educational knowledge of the population": conversation on the topic "seven neighborhood parents for a child", Organization of evenings: class, group implementation of parental meetings: Organization of the event "day of open doors": establishment of the, to set up events to go to theaters "prosperous neighborhood", "neighborhood Organization of meetings, evenings of" the furnace of culture"," responsible family " and

transfer.

XII. Direction:-spiritual and educational activity carried out by the higher educational institution with public organizations. To organize scientific, technical, cultural, sports and Physical Culture associations of public organizations, to establish activities in cooperation with public organizations such as the Youth Union, Trade Union, Women's party. After the lesson, establish pedagogical leadership over spiritual and educational work of students. The work on the mentioned spiritual and educational direction is planned in the academic year. On the basis of the annual plan, monthly and weekly managed work is drawn up.

In order to carry out spiritual and educational activities in the directions mentioned above, the work is drawn up and planned for the academic year or the main year.

Spiritual and educational activity is organized in different forms. This can be divided into about three groups:

Individual (individual) Affairs.

Works circle.

Mass work.

Individual spiritual and educational activities include Olympiads, competitions with senior students, courses, visions. Although many participate in this form of events, we call it individual spiritual and educational activity, since each participant individually participates in it, protects the educational institution, the region by a certain type of event. Scientists of science-this is the most important means of developing interest in knowledge. Its educational value is that, although it is conducted in a certain science, the individual assignments, questions that are formed in it, serve to develop the creative thinking of the student, to seek knowledge.

The choice of individual spiritual and educational activity and the type in the form of a spectacle also develop creativity, purposefulness for students and young people. For example: the student participates in such contests and exhibitions as "mohir Eller", "technical creativity", "poetry mask", each of which demonstrates his creativity, ability, talent. These competitions start from the institution of higher education and bring up feelings of responsibility, pride, struggle for Honor in the student due to the fact that they are held at the Republican level.

\section{RESULTS}

At present, the most common form of spiritual and educational activity in educational institutions is the work of this circle. Circles of Science in higher education institutions, artistic amateur, photo, radio, cinema clubs, "young literate", "young bookstore", "young educator" and clubs also have great educational significance.

Participation in clubs and clubs along with the development of cognitive abilities, creative thinking serves students kuchaytirishga their responsibility before the country, Vatan, the people and therefore serves to increase the spiritual and educational potential of the younger generation.

Another form of spiritual-educational activity is mass events. To this, there are fairy tales, themed evenings, dispatches, question-and-answer nights, conferences, festivities, sports holidays and games, excursions, etc.the G.products included.

So kilib is a wide coverage of spiritual and educational activity. After all, spirituality and enlightenment is a higher value. It reflects the traditions of our people, the teachings of our thinkers, the way of life of our historical national heroes, the hard life of those who fought for independence and freedom. Therefore, it is also a high value. He accomplishes such a great goal as educating a perfect person according to his directions.

\section{CONCLUSION}

If we carry out the above-mentioned thoughts, works, spiritual and educational activity has reached its provisions, the foundation stone for the formation of a harmonious generation will be laid. To do this, it is necessary to constantly research, try to lose weight. It is necessary to make maximum use of the opportunities in spiritual and educational activities.

Thus, the spiritual and educational activity, organized in educational institutions, increases the thirst of students and young people for knowledge, along with the development of mental well-being and intelligence, creates the basis for their spiritual harmonious upbringing. 


\section{REFERENCES}

1. Mirziyoyev Sh.M. The work of his intention is also great, his life is light, and his future will be prosperous. - Tashkent:" Uzbekistan " NMIU, 2019. - 400 b.

2. In the "circle of education" of the Republic of Uzbekistan, Law, - Tashkent, 1997.

3. "National program of Personnel Training". - Tashkent, 1997.

4. Pedagogy.// puddles of anger. A. Under the pseudonym Munavvarov-Tashkent, "okitici", 1996.

5. Forming the spirituality of the reader "Shark", 2000.

6. Omarov B, Alimov Sh. Fundamentals of spiritual and educational education in higher educational institutions. - T: "Science", 2004. 